\title{
Cultivable Bacterial Community Analysis of Dairy Activated Sludge for Value Addition to Dairy Wastewater
}

\author{
Tethi Biswas ${ }^{1,2}$, Debasmita Chatterjee ${ }^{3}$, Sinchini Barman ${ }^{3}$, Amrita Chakraborty $^{1}$, Nabanita Halder ${ }^{1}$, Srimoyee Banerjee ${ }^{1}$, \\ and Shaon Ray Chaudhuri ${ }^{1}$ * \\ ${ }^{1}$ Department of Microbiology, Tripura University, Suryamaninagar, Tripura West, 799022, India \\ ${ }^{2}$ Centre of Excellence in Environmental Technology and Management, ${ }^{3}$ Department of Biotechnology, Maulana Abul Kalam Azad University \\ of Technology, Haringhata, Nadia, West Bengal-741249, India
}

Received: January 29, 2019 / Revised: April 18, 2019 / Accepted: April 29, 2019

\begin{abstract}
Analysis of bacterial communities based on their 16S rDNA sequences revealed the predominance of Proteobacteria (Aeromonas sp., Acinetobacter sp. and Thaueraamino aromatica sp.) and uncultured bacterium in activated sludge from the effluent treatment plant (ETP) of Mother Dairy, Calcutta (India). Each isolate was used for bioremediation of dairy wastewater with simultaneous conversion of nitrogenous pollutants into ammonia. A consortium developed using seven of these isolates and three Bacillus strains from different environmental origins could reduce $93 \%$ nitrate with simultaneous production of ammonia $(626 \mu \mathrm{g} / 100 \mathrm{ml})$ within $20 \mathrm{~h}$ in non-aerated, immobilized conditions as compared to $82 \%$ nitrate reduction producing $2.4 \mu \mathrm{g} / 100 \mathrm{ml}$ ammonia in $96 \mathrm{~h}$ with extensive aeration in a conventional ETP. The treated ammonia-rich effluent could be used instead of freshwater and fertilizer during cultivation of mung bean with 1.6-fold increase in grain yield. The ETP with the surrounding agricultural land makes this process a zero liquid discharge technology for using the biofertilizer generated. In addition, the process requires minimal energy supporting sustained environmental health. This method is thus proposed as an alternative approach for small-scale dairy ETPs.
\end{abstract}

Keywords: Dairy wastewater, activated sludge, bioremediation, bacteria, biofertilizer

\section{Introduction}

Operation Flood, the world's biggest dairy development program launched by National Dairy Development Board (NDDB), India in 1970 under the leadership of Mr.V. Kurien, started with an objective of creating a milk grid nationwide and has made India world's largest producer of milk [1] from a milk-deficient nation. This production is associated with simultaneous release of copious amount of nutrient rich wastewater which could

\section{*Corresponding author}

Tel: +919831034236, Fax: +913812374802

E-mail: shaon.raychaudhuri@gmail.com

(c) 2019, The Korean Society for Microbiology and Biotechnology support microbe as well as plant growth. For every litre of milk processed in India, about 1 to $10 \mathrm{~L}$ of water is utilized [2] depending on the end products such as butter, cheese, and yoghurt. This nutrient-rich [3] effluent if discharged (untreated or partially treated) into the water bodies will cause eutrophication while increasing the salinity of the soil. The effluent needs to be treated using an energetically intensive, laborious and elaborate process (Fig. 1A) requiring about 105 to $120 \mathrm{~h}$. The establishment cost of an effluent treatment plant (ETP) to process about $10 \mathrm{~m}^{3}$ dairy wastewater (DWW) is approximately 15200 US Dollar with a running cost of about 1.2 to $2 \%$ of the revenue generated. For an aeration tank of $2.1 \mathrm{~m}^{3}$, six to seven propellers of 7.5 horse- 
A

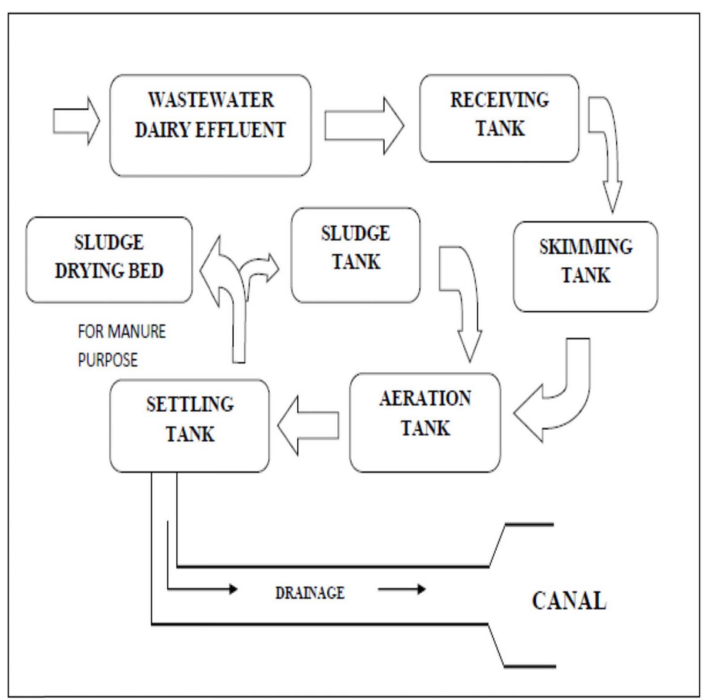

C

\begin{tabular}{|c|c|c|c|}
\hline Isolates & Nearest Neighbour & $\%$ identity & GeneBank Acc no. \\
\hline MDS 1 & Aeromonas sp. & $99 \%$ & JX126137 \\
\hline MDS 3 & Aeromonas punctata & $98 \%$ & \\
\hline MDS 5A & Aeromonas caviae & $99 \%$ & JX126140 \\
\hline MDS 5B & Thaueraamino aromatica sp & $99 \%$ & \\
\hline MDS 6 & Uncultured bacterium & $96 \%$ & \\
\hline MDS 7A & Acinetobacter sp. & $97 \%$ & JX126141 \\
\hline MDS 7B & Aeromonas hydrophila & $98 \%$ & JX126144 \\
\hline MDS 8 & Aeromonas sp. & $98 \%$ & AOTK01000000 \\
\hline
\end{tabular}

E

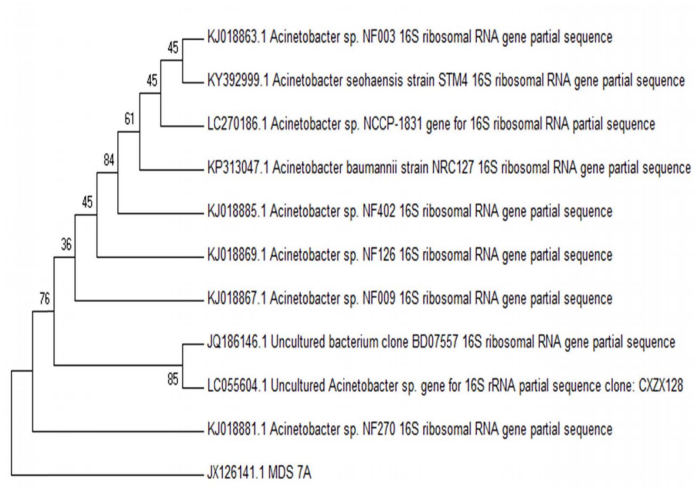

B

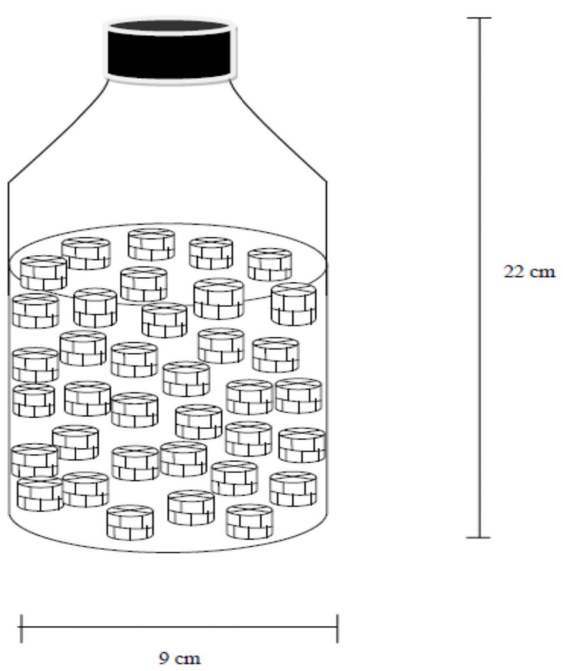

D

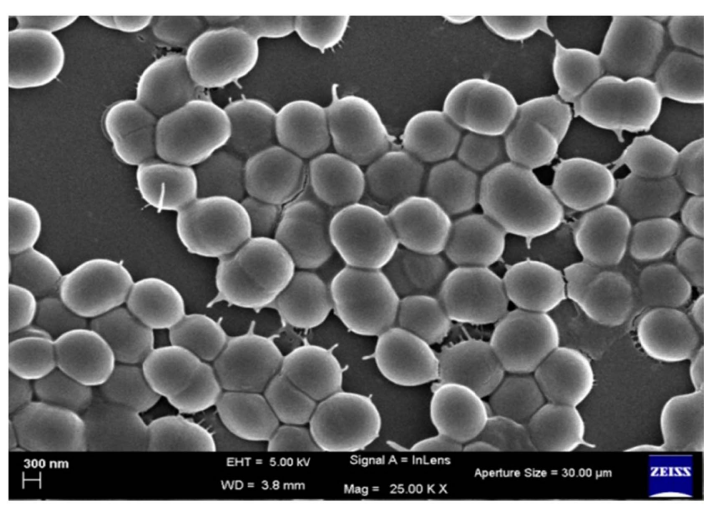

F

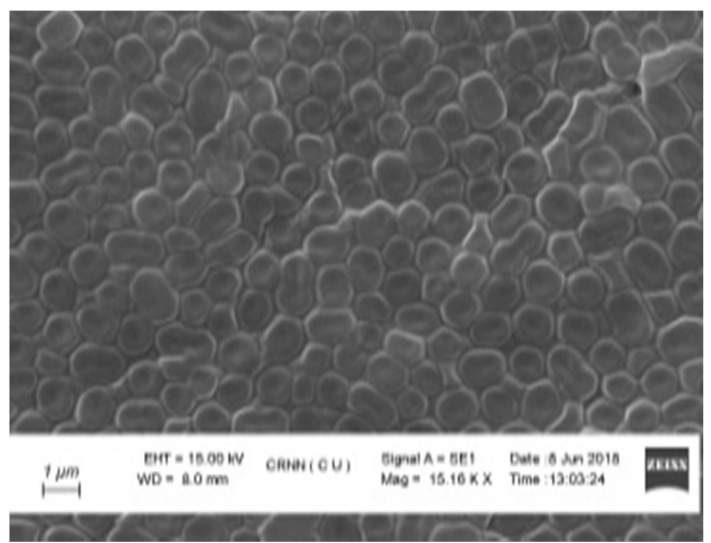

Fig. 1. (A) Pictorial representation of a conventional system of dairy effluent treatment plant. (B) Schematic diagram of the $1 \mathrm{~L}$ bioreactor. (C) Molecular identity of the isolated strains. (D) Field Emission Scanning Electron Microscopic image of MDS 7A showing the cell morphology. (E) Phylogenetic tree of partial 16S rDNA sequences of MDS 7A constructed using MEGA7, (F) Scanning Electron Microscopic image of the consortium under environmental mode showing the cells in biofilm state. 
power work round the clock for $24 \mathrm{~h}$, making the process expensive and difficult for the medium and small-scale set-ups to adopt. This necessitates looking for alternative options.

Numerous research groups are working on different aspects of DWW treatment to improve the existing system which consists of anaerobic and aerobic processes. Existing anaerobic treatment methods $[4,5]$ are energetically balanced, with no oxygen requirement and reduced problem of sludge bulking [6]. However, there are a few drawbacks associated with the anaerobic treatment processes. The lipids present in dairy effluents pose severe problems by virtue of floc formation and floatation within reactors. The lipids also reduce nutrient availability to cells in case of biofilm reactors and often the products of lipid breakdown inhibit other microbial processes such as methane production [7]. Aerobic treatment of the DWW [8, 9] may utilize membrane bioreactor [10], sequencing batch reactors [11] and the activated sludge process for the treatment of this kind of wastewater. However, the aerobic treatment process also has certain drawbacks. It is much more time consuming; often taking around $96 \mathrm{~h}$ of retention time depending on the initial chemical oxygen demand (COD) load [12]. The activated sludge process requires high energy inputs [13] while leading to the formation of huge quantities of solid bulks [14]. The existing treatment process is not affordable for the small and middle segment of dairy ETP.

In order to ensure complete treatment of DWW by small and middle scale Dairy ETP with minimal environmental impact in an economically viable manner, appropriate treatment strategy needs to be developed. It should ensure minimum energy and time consumption with generation of value added product. In order to do so, well characterized bacterial isolates from appropriate environmental origin can be combined in different proportions to develop consortium with desired performance like conversion of nitrogenous pollutants into ammonia in this case. Once developed, the consortium could be used in biofilm reactors to ensure one time microbial charging, minimum maintenance and resistance to pollutant shock load with sustained performance over a long period of time and minimum dead mass generation.

In thist study, we attempted to develop the above mentioned system at the laboratory scale. The first step would be to characterize the bacteria in the activated sludge involved in the biological treatment of the dairy effluent and the second step would be the development of an efficient consortium for DWW treatment and test the efficiency of the treated effluent as a plant growth nutrient.

\section{Materials and Methods}

\section{Characterization of the wastewater}

The influent as well as effluent from the Mother Dairy Calcutta ETP at West Bengal, India $\left(22.6828^{\circ} \mathrm{N}\right.$, $88.3062^{\circ} \mathrm{E}$ ) were collected in sterile glass containers and carried to the laboratory for further analysis. It was stored at $4{ }^{\circ} \mathrm{C}$ until further investigation. The physical parameters (colour, $\mathrm{pH}$, odour), chemical parameters (calcium carbonate, ammonia, chloride, nitrate, nitrite, phosphate, residual chlorine, biological oxygen demand (BOD), total carbohydrate content, total protein content) and biological parameters (Escherichia coli, Enterobacter aerogenes, Shigella flexneri, Klebsiella pneumonia, Pseudomonas aeruginosa, Proteus mirabilis, Enterobacter faecalis, Salmonella sp. and Staphylococcus aureus) were analysed according to the Guide manual: Water and Wastewater analysis of Central Pollution Control Board (CPCB), India [15].

\section{Screening and characterization of isolates}

The activated sludge from the ETP was collected in sterile $50 \mathrm{ml}$ centrifuge tubes (Tarson, Cat No. 546041), transported to the laboratory, and stored at $4{ }^{\circ} \mathrm{C}$ before being used.

The sludge samples were diluted $\left(10^{-3}\right.$ to $\left.10^{-4}\right)$ aseptically in Phosphate Buffered Saline (PBS) (8.01 gm sodium chloride, $0.2 \mathrm{gm}$ potassium chloride, $1.78 \mathrm{gm}$ di-sodium hydrogen phosphate and $0.27 \mathrm{gm}$ potassium di-hydrogen phosphate with a final $\mathrm{pH}$ of 6.5), vortexed at highest speed for a minute and were spread on Luria Bertani (LB) agar (1\% tryptone, 0.5\% yeast extract, $0.5 \%$ sodium chloride, $1.5 \%$ bacteriological agar; $\mathrm{pH} 7.5)$. The plates were incubated for $12 \mathrm{~h}$ at $37^{\circ} \mathrm{C}$ in an inverted position. The different types of colonies were selected and subsequently streaked consecutively for three rounds on LB Agar plates to obtain pure cultures. The pure isolates obtained were characterized in detail as 
per standard procedure [16]. Under morphological characterization, the cell and colony morphology were noted. For a better understanding of the morphology, the overnight grown cells were observed under Scanning electron microscope in environmental mode (Quanta 250, FEI). For isolates, MDS 1, MDS 5A and MCC 2139 further analysis was done using the Field Emission scanning electron microscope \{Supra 55 (Serial number 4132)\}. The Gram nature and extracellular enzyme (lipase, protease, amylase, DNAse, lecithinase, oxidase, catalase, and phosphatase) producing ability were checked as part of the isolates' biochemical characterization. Antibiotic susceptibility, substrate utilization profile, $\mathrm{pH}$ as well as temperature optimization for growth were carried out to understand the isolates' physiological characteristics as per the standard procedure. The biofilm-forming ability is an important criterion for the characterization of bacteria and more important if it needs to be used for the development of a biofilm reactor which could be used for wastewater treatment in a continuous mode. The formation of biofilm by the isolates was tested using Martin's method [17] with minor modification. The isolates were incubated for $24 \mathrm{~h}$ instead of $12 \mathrm{~h}$ at $37^{\circ} \mathrm{C}$ in $\mathrm{LB}$ medium in 24 well microtiter plate (NEST, Cat No. 702001). This variation was due to the need to test them at the maturation stage of biofilm formation. The strains were characterized at the molecular level using partial $16 \mathrm{~S}$ rDNA sequencing as per the standard procedure. The sequence of the forward and reverse primers was AGAGTTTGATCMTGGCTCAG and TACGGYTACCTTGTTACGACTT respectively. The polymerase chain reaction (PCR) was run for 25 cycles with an initial denaturation at $96^{\circ} \mathrm{C}$ for $5 \mathrm{~min}$, denaturation at $96^{\circ} \mathrm{C}$ for $30 \mathrm{~s}$, hybridization at $50^{\circ} \mathrm{C}$ for $30 \mathrm{~s}$ and elongation at $60^{\circ} \mathrm{C}$ for 1.30 min. The PCR products were subjected to TA cloning and the positive clones were used for sequencing the inserts. For sequencing, the sequencing mixture $(10 \mu \mathrm{l})$ consists of Big Dye Terminator Ready Reaction Mix (4 $\mu \mathrm{l})$; Template (100 ng); Primer (20 pmol). The sequencing was carried out on a 3500 ABI Platform. The sequences were subjected to nucleotide BLAST analysis at National Center for Biotechnology Information (NCBI) and the closest neighbours were documented. The novel sequences were submitted to GenBank and the corresponding accession numbers were obtained (Fig.
1C). The phylogenetic trees were constructed for the submitted sequences using MEGA7 [18].

Since these isolates were indigenously present in the dairy activated sludge with high BOD load along with nitrate, phosphate and other contaminants acting as a selective pressure, it was expected that they would have an inherent ability for bioremediation. The different isolates were checked for their ability to reduce carbohydrate, protein, nitrate, nitrite, chloride, calcium carbonate and phosphate according to standard protocols [15, 1921] following $16 \mathrm{~h}$ of incubation at $37^{\circ} \mathrm{C}$. The isolates were tested for their ability to produce ammonia in planktonic as well as biofilm state following $16 \mathrm{~h}$ of incubation at $37^{\circ} \mathrm{C}$ under stationary condition. The selection of stationary condition for monitoring ammonia production was based on earlier studies [22] carried out in the laboratory for DWW treatment.

\section{Development of consortium}

Keeping in mind the complex nature of the dairy effluent and the different pollutants to be treated, a consortium was prepared with the goal of bioremediation of the wastewater with enhanced ammonia production from the waste. The consortium with ten isolates (seven from dairy activated sludge, one from marine coastal waters [23], one from biomass of the low-level radioactive wastewater treating bioreactor [24, 25] and one from the rhizosphere of water lily [26]) combined in 1:1 proportion was developed to obtain simultaneous reduction of nitrate and phosphate from DWW with associated ammonia production. The 1:1 proportion was based on an earlier optimization study for the development of bacterial consortium for selective conversion of nitrogenous pollutants to ammonia under ambient condition [22]. Earlier reports by our group have revealed the minimization of bacterial dead mass during wastewater treatment using tailor-made consortium [27-29]. The selection of isolates was based on their ability to remove nitrate and phosphate. Since biofilm-based systems are known to perform better as compared to their suspended counterparts [28-31], the consortium was tested for its performance under the immobilized condition and visualized under a Scanning electron microscope in environmental mode (ZEISS EVO-18). For forming the biofilm, $4 \%$ inoculum of the developed consortium $\left(1.9 \times 10^{9}\right.$ Colony Forming Unit/ml after $12 \mathrm{~h}$ of growth) was 
added to $\mathrm{LB}$ broth in $1 \mathrm{~L}$ bioreactor with 100 Pall rings (diameter $0.022 \mathrm{~m}$ and height $0.016 \mathrm{~m}$ ) used as immobilization matrix (Fig. 1B). The system was allowed to stand at $37^{\circ} \mathrm{C}$ for $24 \mathrm{~h}$ for the microbes to grow and stick to the matrix. The culture was decanted, the system was left aseptically for six hours to facilitate further stabilization of the stuck bacteria on the matrix and finally, DWW was added for setting up the biofilm reactor. This was considered as the zero-day of the experiment. The consortium in the biofilm reactor at ambient temperature $\left(25-28^{\circ} \mathrm{C}\right)$ operated under batch mode was tested for its sustained activity over a period of 20 days with sampling at the $20^{\text {th }}$ hour for 14 days. Based on the results obtained, the sampling from the $15^{\text {th }}$ to the $20^{\text {th }}$ day was done at the $6^{\text {th }}$ hour, $16^{\text {th }}$ hour and $20^{\text {th }}$ hour for monitoring nitrate reduction and ammonia production while at the $6^{\text {th }}$ hour and $16^{\text {th }}$ hour for the phosphate reduction.

As fat is an integral part of wastewater generated from dairy industries, the consortium has also been checked for its fat removal efficiency from the fat-rich DWW after $24 \mathrm{~h}$ of incubation at $37^{\circ} \mathrm{C}$. After incubation was over, the fat content was measured and compared with that of control (initial fat content in the wastewater). For the measurement, the oil-water separation method was adopted where n-hexane was used with the wastewater in a 1:20 ratio for the separation of fats from the wastewater. The oily layer after separation from the aqueous layer was collected, hexane was allowed to evaporate and, the remaining dried fat content was weighed. The same was checked for the wastewater churned for $90 \mathrm{~s}$ prior to treatment. This was done to suspend the fat as smaller particles/droplets thus ensuring better microbial interaction.

Each set of data was statistically validated using single-factor ANOVA at a significance level of 0.05 using Microsoft Excel 2007.

\section{Results and Discussion}

\section{Characterization of the DWW and isolates}

The influent and the effluent were characterized for a better understanding of the system (Supplementary Table 1). It is of utmost importance to understand the nature of the effluent for developing appropriate treatment strategy and accessing the efficiency of the adopted process. The treated effluent met the CPCB discharge limit for most of the pollutants but involves utilization of large space in terms of ETP area; enormous energy consumption in terms of mixing in the aeration chamber as well as the discharge of copious amount of treated effluent to the environment.

To understand the microbes involved in the bioremediation, the activated sludge was analyzed for its microbial population. The cultivable microbial population of the activated sludge revealed the presence of eight different types of bacteria (Supplementary Table 2, 3, 4; Fig. 1C, Fig. 1D, Fig. 1E) which were closest to Aeromonas sp., Acinetobacter sp., Thaueraamino aromatica sp. and uncultured bacterium at the molecular level using partial 16S rDNA sequence analysis (Fig. 1C, Fig. 1E). The above data reflects that through this approach, microbes that were reported to be uncultivable could be cultivated under laboratory conditions. All the isolates were Gram-negative, DNase, and Lecithinase nonproducers. Amongst all, MDS 7A (MCC2139) could only utilize Esculin (Supplementary Table 3) out of the 35 different substrates tested. It was resistant to almost all antibiotics tested while showing intermediate sensitivity to Doxycycline hydrochloride (DO) and Ciprofloxacin (CF) (Supplementary Table 4).

An absorbance of 0.2 to 0.35 at $620 \mathrm{~nm}$ reflects structured biofilm while that above 0.65 indicates strong biofilm formation [17]. Out of these 8 isolates (Supplementary Table 2) only MDS7B was a weak biofilm former; MDS7A was moderate biofilm former while the other 6 were strong biofilm formers. This result indicates them to be desirable candidates for biofilm reactor-based studies.

\section{Bioremediation of DWW}

Since the principle focus of this study was to know the microbes involved in the process of bioremediation, the isolates were individually tested (Fig. 2) for their ability to reduce carbohydrate (Fig. 2A), protein (Fig. 2B), chloride (Fig. 2C), carbonate (Fig. 2D), nitrite (Fig. 2E), nitrate (Fig. 2F) and phosphate (Fig. 2G), while producing ammonia (Fig. 2H). Each isolate was found to reduce protein, carbohydrate, nitrate, nitrite, and carbonate indicating their direct involvement in the process of bioremediation. The production of ammonia indicates their ability to convert organic pollutants into ammonia in a $\mathrm{C} / \mathrm{N}$ rich condition as observed in DWW. Though 
A

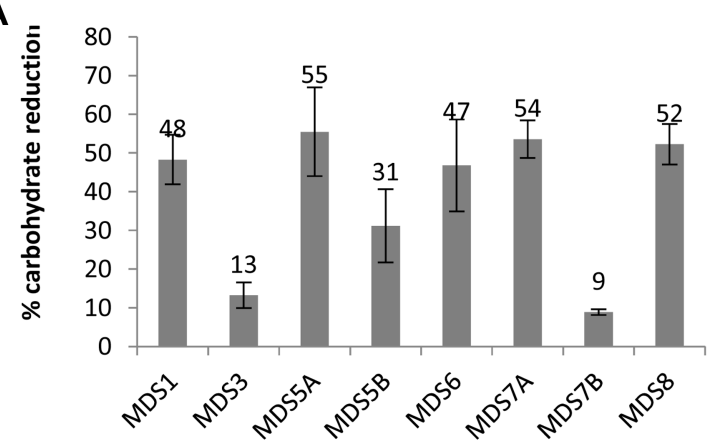

C

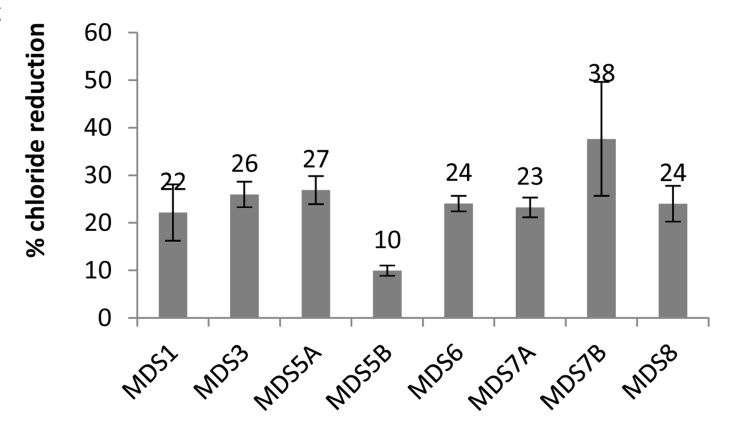

E

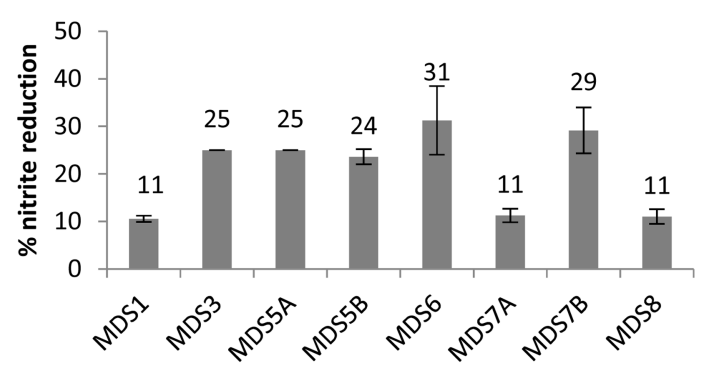

G

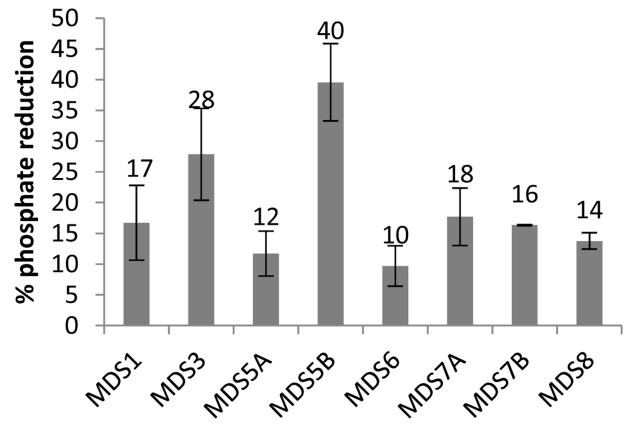

B

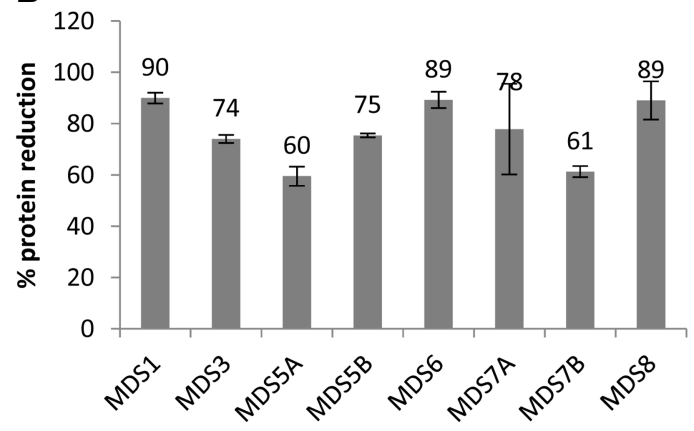

D

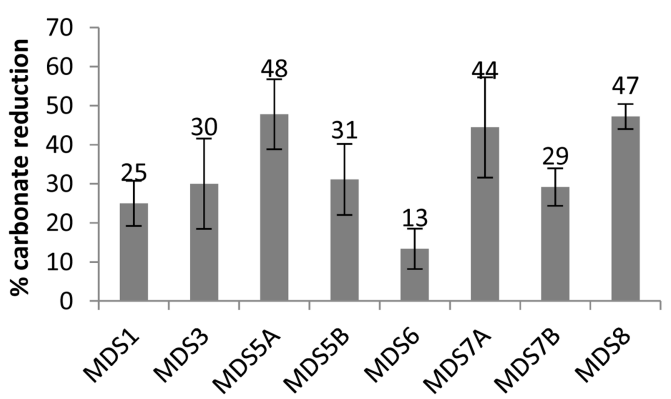

$\mathbf{F}$
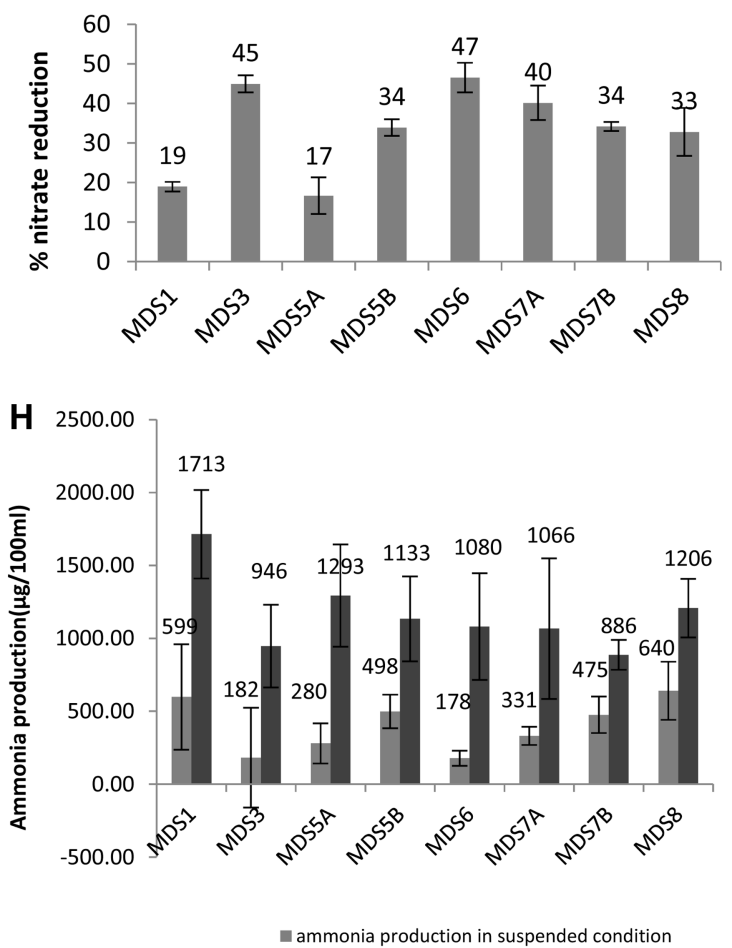

- ammonia production in immobilized condition

Fig. 2. (A-G) represents graphs showing pollutant removal ability of the pure isolates. $H$ represents a graph showing ammonia production by the isolates in suspended and immobilized condition. Ammonia production is significantly high in case of immobilized condition under ambient pressure at $37^{\circ} \mathrm{C}$ from the DWW. 
ammonia is toxic to aquatic life forms; it acts as a plant growth nutrient in adequate concentration during soil application. Nitrogen (N) is an essential source of nutrition for growing plants. Ammonia has the highest $\mathrm{N}$ content among the commercial fertilizers. Biological production of ammonia from wastewater and its reuse would reduce the use of chemical fertilizers simultaneously converting the waste into a by-product. As nitrate is assimilated via conversion to nitrite, ammonia and then into amino acids, the supply of ammonia requires less energy input by the plant because the $\mathrm{N}$ here is already in a reduced form by-passing the initial steps in assimilation. These isolates were further able to reduce chloride and phosphate indicating their ability to handle the waste generated as an outcome of the Clean-in-place (CIP) practice followed in these industries. The extent of removal of carbohydrate, carbonate, nitrite, nitrate and phosphate by the pure isolates were much less than that of the conventional ETP indicating the physicochemical processes to be actively involved in reducing these components (Supplementary Table 1 and Fig. 2). Moreover, there might be other microbes actively involved in these reductions but could not be cultivated using the chosen medium. The protein content reduction in the ETP was comparable to that by the pure isolates. There was better removal of chloride leading to cell growth indicating less involvement of the physicochemical process in chloride removal. Under a low $\mathrm{C} / \mathrm{N}$ ratio, the nitrogenous pollutants get converted to nitrogen gas while during high $\mathrm{C} / \mathrm{N}$ ratio (as in case of DWW) it moves towards the production of ammonia [32]. Ammonia is used for various purposes. When produced at $37^{\circ} \mathrm{C}$ temperature and atmospheric pressure [33] in a substantial amount, it might be extracted. However, when produced in concentrations that could not be extracted in an economically viable manner, it could be used as a biofertilizer [22]. The ability of these isolates to convert the nitrogenous component in DWW into ammonia was evaluated. The production ranges from 178 to $641 \mu \mathrm{g} / 100 \mathrm{ml}$ (Fig. 2H) under a suspended condition. The possible pathway of nitrate reduction to ammonium could be dissimilatory nitrate reduction to ammonium (DNRA), under limited oxygen conditions. Unlike denitrification, it acts to conserve nitrogen in the system, producing soluble ammonium rather than nitrogen gas. Another source of nitrogen in the DWW is the milk protein. Ammonium ions are formed during the breakdown of amino acids. A major concern regarding the consistent performance of a biological system is maintaining the microbial population during the entire span of the operation. Biological systems are an integral part of DWW treatment which goes hand in hand with physico-chemical process. The microbial composition needs to be maintained during the course of their operation for sustained performance. This concern could be addressed by using biofilm-based system instead of suspended culture. The biofilm-based system in each case (Fig. $2 \mathrm{H}$ ) produced significantly ( $p$ value 7.16E-06) higher concentration of ammonia by these isolates (887 to $1713 \mu \mathrm{g} / 100 \mathrm{ml}$ ) (Fig. $2 \mathrm{H}$ ) as compared to their suspended states revealing their ability to converting nitrogenous pollutants in DWW into ammonia (principle component of liquid biofertilizer). This is an important criterion for selection of the bacterial isolates for consortium development. In this case, the microbes could produce an economically important by-product from wastewater instead of using enriched or selective media. Also, they could produce ammonia just in a range that is acceptable for the plant application which otherwise, in a higher concentration could become toxic [34] for soil and the receiving water bodies (after seepage). Fig. 2(A-G) clearly revealed bioremedial activity of each isolate. However, the discharge level for nitrate (10 mg/l as per CPCB) could not be reached either by the pure isolates or during conventional treatment that was studied.

\section{Development of tailor-made consortium}

An attempt was made to develop consortium with the objective of getting the nitrate from DWW to discharge level with the simultaneous production of ammonia. Three different Bacillus sp. (MCC0008, MCC2059, MCC0120) isolated from the varied origin with nitrate and phosphate removing ability [23-26] were added in 1:1 ratio to 7 of the isolates from dairy activated sludge \{MDS1, MDS5A, MDS5B, MBS6, MDS 7A (MCC2139), MDS7B, MDS8 (MCC2167)\} to evolve the consortium. The strong biofilm-forming (O.D at $620 \mathrm{~nm}=0.78)$ consortium revealed uniform biofilm under scanning electron microscopy (Fig. 1F) with synergistic effect for targeted end product generation with minimum sludge production. However, this consortium could also reduce phosphate to just above the discharge level. 


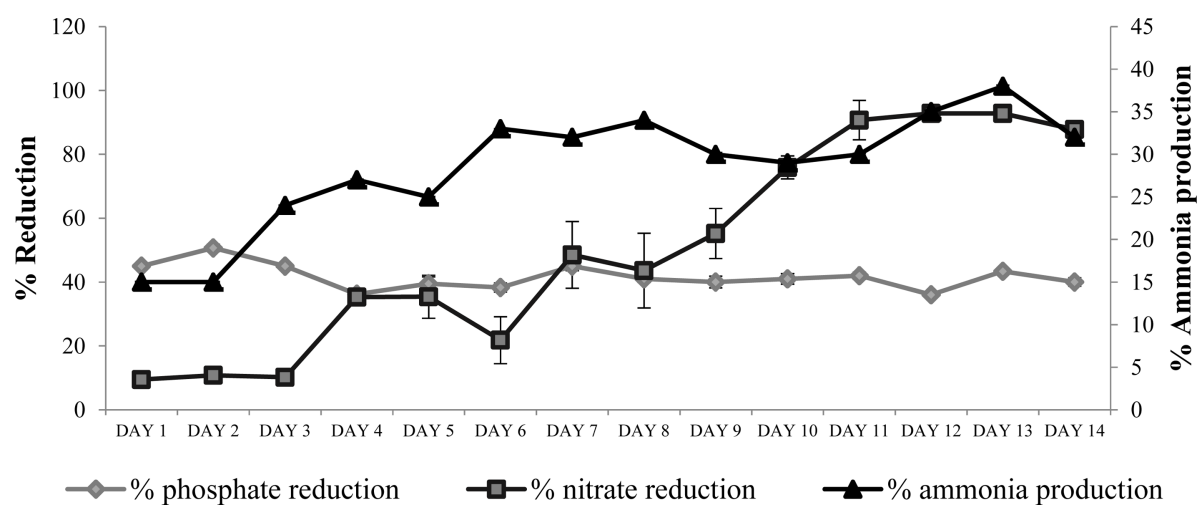

Fig. 3. Graph showing percentage nitrate and phosphate reduction and simultaneous ammonia production in a one litre biofilm reactor after $20 \mathrm{~h}$ of incubation at ambient conditions.

The consortium in a $1 \mathrm{~L}$ biofilm reactor at ambient temperature $\left(25-28^{\circ} \mathrm{C}\right)$ operating under batch mode (Fig. 1B) was tested for its sustained activity at every $20^{\text {th }}$ hour for 14 days through analysis of nitrate, phosphate and ammonia concentration (Fig. 3). The performance of the reactor stabilized from day one for phosphate reduction; day 6 for ammonia production while day 11 for nitrate reduction. The nitrate reduction was $93 \%$ (from $115 \mathrm{ppm}$ to $8 \mathrm{ppm}$ ) and the ammonia production was $626 \mu \mathrm{g} / 100 \mathrm{ml}(38 \%)$ with phosphate reduction of $45 \%$. For $15^{\text {th }}$ to the $20^{\text {th }}$ day the major nitrate reduction was at $16^{\text {th }}$ hour while reaching discharge level only at the $20^{\text {th }}$ hour of incubation $\left\{35 \% \pm 2.5\left(6^{\text {th }}\right.\right.$ hour $), 80 \% \pm 2.4$ ( $16^{\text {th }}$ hour), $95 \% \pm 3.6$ ( $20^{\text {th }}$ hour); $p$-value $\left.1.38 \mathrm{E}-15\right\}$. Ammonia production increased significantly ( $p$-value $5.16 \mathrm{E}-12)$ with time showing maximum production at $20^{\text {th }}$ hour. The values were $7 \% \pm 1.1,26 \% \pm 2.7,34 \% \pm$ 2.5 at the $6^{\text {th }}, 16^{\text {th }}$ and $20^{\text {th }}$ hour of incubation; a pattern similar to that of nitrate reduction. In case of phosphate, the reduction was measured at $6^{\text {th }}(60 \% \pm 7.0)$ and $16^{\text {th }}$ $(41 \% \pm 1.2)$ hour with higher reduction at the $6^{\text {th }}$ hour ( $p$ value 5.37E-05). The reason behind this decreased reduction from $6^{\text {th }}$ to $20^{\text {th }}$ hour was due to the release of polyphosphate under the anoxic condition and its conversion to inorganic phosphate $(\mathrm{Pi})$ by the phosphatase enzyme produced by the microbes (Supplementary Table 2). The immobilized biofilm system could reduce COD by $72 \%$ (from $16.5 \mathrm{~g} / \mathrm{l}$ to $4.5 \mathrm{~g} / \mathrm{l}$ ) and the total nitrogen loss was recorded to be $26 \%$ (from $46.2 \mathrm{mg} / \mathrm{l}$ to $34.3 \mathrm{mg} / \mathrm{l}$ ) within $20 \mathrm{~h}$. The decrease in reduction percentage of total nitrogen compared to nitrate reduction is due to the production of ammonia in the system. Total nitrogen is the sum of total Kjeldahl nitrogen (ammonia, organic and reduced nitrogen).

The reactor once charged with bacterial biofilm, could be used repeatedly with consistent performance. But for phosphate the discharge level (5 mg/l as per CPCB) was not reached. This phosphate could be picked up by soil (rhizosphere) to enable the plants to utilize the same. The nitrate reduction led to a final concentration of $5 \mathrm{mg} / \mathrm{l}$ which was below the CPCB discharge level $(10 \mathrm{mg} / \mathrm{l})$ with associated ammonia production $(626 \mu \mathrm{g} /$ $100 \mathrm{ml}$ ) at room temperature under ambient pressure. The production could be further increased by operating the reaction at $37^{\circ} \mathrm{C}$. Thus the consortium was involved in conversion of nitrogenous compounds in DWW to ammonia, an easily utilizable form of nitrogen by plants. The $\mathrm{C} / \mathrm{N}$ ratio of the growth medium determines the specific metabolic pathway functional in a microbe [32, 33] under a given condition. Since the $\mathrm{C} / \mathrm{N}$ ratio of DWW is high owing to the high organic load, the preferred metabolic pathway for conversion of the nitrogenous substances would be nitrification followed by ammonification. Dissimilatory nitrate reduction processes, including denitrification, anaerobic ammonium oxidation (ANAMMOX), and dissimilatory nitrate reduction to ammonium (DNRA), are important pathways of nitrate transformation in aquatic environments. While denitrification and ANAMMOX removes nitrate through nitrate reduction and ammonium oxidation respectively to nitrogen gas, DNRA does not remove nitrate but instead reduces it to ammonium. Therefore, DNRA still retains the transformed nitrogen as a biologically available form. Organic matter contents are considered as a cru- 
cial variable for ammonium production via DNRA [35]. The DNRA rates correlates with organic matter content acting as substrate to supply electron for the nitrate reduction during the DNRA reaction [36]. Some of these isolates have been shown to have the requisite genes for ammonification [33, 37].

The consortium upon incubation for $24 \mathrm{~h}$ at $37^{\circ} \mathrm{C}$, could also remove fat by $37 \%$ from the fat-rich wastewater. The same consortium upon incubation with the $90 \mathrm{~s}$ churned out wastewater prior to treatment, could reduce the fat content by $54 \%$. Churning could emulsify the fats in the wastewater and break them into smaller droplets which in turn could assist the microbes for better reaction and thus removal. This consortium could be preserved as glycerol stock like the pure isolates.

\section{Reusing treated DWW as liquid biofertilizer}

The reuse of the treated effluent was undertaken through pot trials for Mung bean (var. Meha) cultivation from February to May 2017 at Maulana Abul Kalam Azad University of Technology, West Bengal, India $\left(22.5965^{\circ} \mathrm{N}, 88.4173^{\circ} \mathrm{E}\right)$. The experiment was conducted in triplicate with control set being irrigated with tap water, set 1 being irrigated with untreated DWW while set 2 being irrigated with microbially treated DWW. The irrigation was done once a day with $50 \mathrm{ml}$ water, untreated DWW and treated DWW (whichever is applicable) per $8 \mathrm{~kg}$ of soil. Preliminary results show a 1.6fold increase ( $p$-value $3.043 \mathrm{E}-03$ ) in yield following treated DWW application compared to control. No significant change ( $p$-value 0.15941$)$ in yield was observed using untreated DWW when compared to control. Meer presence of high $\mathrm{C} / \mathrm{N}$ ration is not sufficient to enhance plant growth but conversion of the nutrients into a plant utilizable form is essential to promote plant growth and yield enhancement [38]. Further optimization is required for developing a regimen for plant growth promotion with a combination of treated effluent with chemical fertilizer to ensure maximum yield enhancement. It would obviate the necessity for purchase of fresh water for irrigation in the farms in the vicinity of the dairies. The associated sustenance of agriculture in these farms would involve very little chemical fertilizer use along with this biofertilizer application for optimum yield enhancement with minimum damage to the environ-

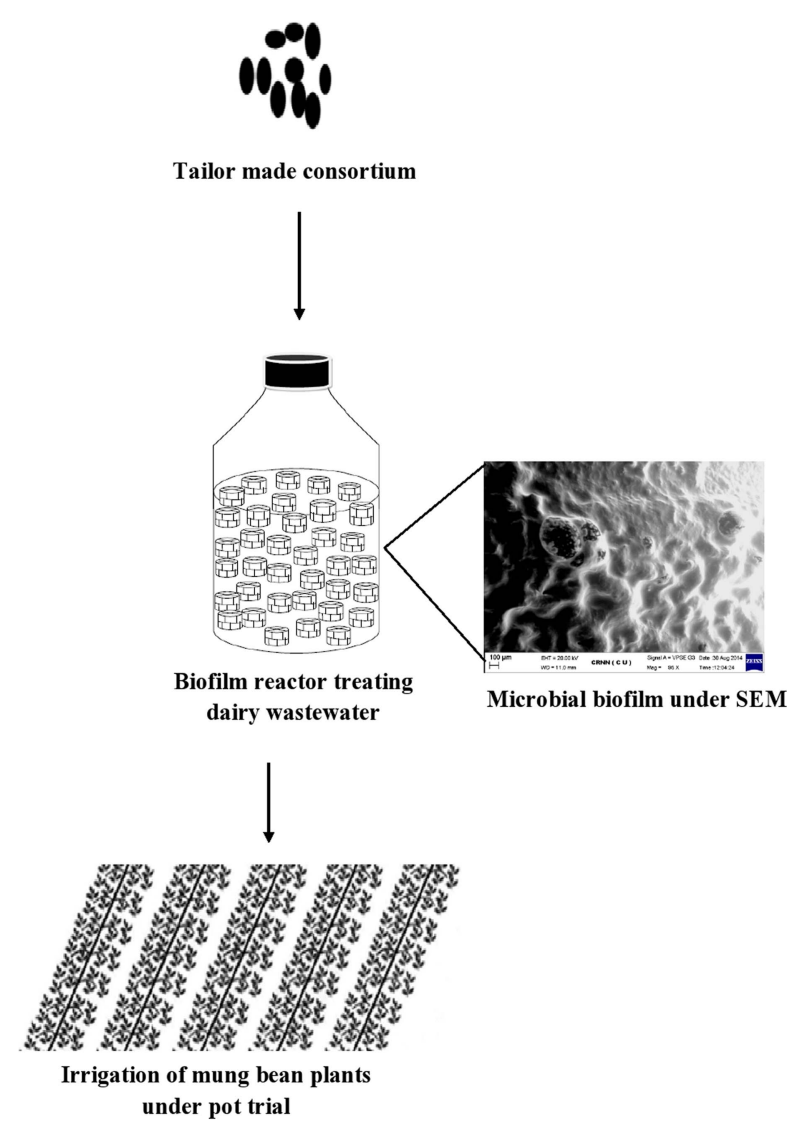

Fig. 4. A schematic diagram summarizing the author's strategy for bioremediation and zero liquid discharge.

ment due to leaching of unutilized chemical fertilizer from the fields into the agricultural runoff. This would help generate revenue in terms of profit from sale of biofertilizer, savings in terms of energy and reduced land requirement for ETP setup.

The single unit operation would enhance the capacity of effluent processing of a conventional 7 unit setup (Fig. $1 \mathrm{~A})$ while cutting down the energy consumption to mild aeration for the last $6 \mathrm{~h}$ of a $26 \mathrm{~h}$ treatment process as compared to 105 to $120 \mathrm{~h}$ in a conventional system. In addition, this process will generate an economically important by-product which would minimize use of chemical fertilizer while replace use of fresh water for agriculture as compared to dischargeable water in case of a conventional system. This would make the process of dairy effluent treatment self-sustaining while protecting the environment through zero liquid discharge (Fig. 4) along with minimal chemical fertilizer leaching. 


\section{Acknowledgments}

The authors would like to thank Mother Dairy, Dankuni for providing the effluent (specially Dr S K Bhowmik and Mr Anisur Rahaman); Institute of Physics, Bhubhaneswar, India for ESEM and Indian Institute of Science Education and Research, Kolkata, India for FESEM facility; Carl Zeiss facility at Center for Research in Nanoscience and Nanotechnology, Kolkata for ESEM of the consortium; Ministry of Human Resource Development, Government of India under the Frontier Area of Science and Technology scheme for the fellowship to TB; Maulana Abul Kalam Azad University of Technology West Bengal as well as Tripura University for providing the laboratory and Computation facility; Prof A R Thakur for helping during sample collection and during the entire course of the study.

\section{Conflict of Interest}

The authors have no financial conflicts of interest to declare.

\section{References}

1. Banerjee A. 2001. Dairying systems in India. Available from http: //www.fao.org/docrep/T3080T/t3080T07.htm. Accessed April 17, 2019.

2. Wojdalski J, Drozdz B, Piechocki J, Gaworski M, Zander Z, Marjanowski J. 2013. Determinants of water consumption in the dairy industry. Pol. J. Chem. Tech. 15: 61-72.

3. Punnagaiarasi A, Elango A, Rajarajan G, Prakash S. 2017. Bioremediation-An Ecosafe Approach for Dairy effluent treatment. pp. 45-50. In Prashanthi M, Sundaram R, Jeyaseelan A, Kaliannan $\mathrm{T}$ (eds.), Bioremediation and Sustainable Technologies for Cleaner Environment, Springer, Cham.

4. Bezerra Jr. RA, Rodrigues JAD, Ratusznei SM, Zaiat M, Foresti E. 2009. Effects of feed time, organic loading and shock loads in anaerobic whey treatment by an AnSBBR with circulation. Appl. Biochem. Biotechnol. 157: 140-158.

5. Dague RR, Habben CE, Pidaparti SR. 1992. Initial studies on the anaerobic sequencing batch reactor. Water Sci. Technol. 26: 24292432.

6. Belancon D, Fuzzato MC, Gomes DRS, Cichello GCV, Pinho SCD, Ribeiro R, et al. 2010. A comparison of two bench-scale anaerobic systems used for the treatment of dairy effluents. Int. J. Dairy Tech. 63: 290-296.

7. Petruy R, Lettinga G. 1997. Digestion of a milk - fat emulsion. Biores. Technol. 61: 141-149.

8. Tocchi C, Federici E, Fidati L, Manzi R, Vincigurerra V, Petruccioli M. 2012. Aerobic treatment of dairy wastewater in an industrial three-reactor plant: Effect of aeration regime on performances and on protozoan and bacterial communities. Water Res. 46: 3334-3344.

9. Schwarzenbeck N, Borges JM, Wilderer PA. 2005. Treatment of dairy effluents in an aerobic granular sludge sequencing batch reactor. Appl. Microbiol. Biotechnol. 66: 711-718.

10. Fraga FA, García HA, Hooijmans CM, Miguez D, Brdjanovic D. 2017. Evaluation of a membrane bioreactor on dairy wastewater treatment and reuse in Uruguay. Int. Biodeterior. Biodegrad. 119: 552-564.

11. Li X, Zhang R. 2002. Aerobic treatment of dairy wastewater with sequencing batch reactor systems. Bioprocess Biosyst. Eng. 25: 103-109.

12. Porges N, Jasewicz L, Hoover SR. 1953. Aerobic treatment of dairy wastes. Appl. Microbiol. 1: 262-270.

13. Charpentier J, Florentz M, David G. 1987. Oxidation-reduction potential (ORP) regulation: a way to optimize pollution removal and energy savings in the low load activated sludge process. Wat. Sci. Tech. 19: 645-655.

14. Liu Y, Tay JH. 2001. Strategy for minimization of excess sludge production from the activated sludge process. Biotechnol. Adv. 19: 97-107.

15. Gautam SP. 2015. Guide manual: water and wastewater_analysis. Central Pollution Control Board, Ministry of Environment \& Forests, Government of India. Available from http://www.indiaenvironmentportal.org.in/files/file/guidemanualw\&wwanalysis. pdf. Accessed April 17, 2019.

16. Nandy P, Thakur AR, RayChaudhuri S. 2007. Characterisation of microbial strains obtained through microbial profiling of urine. OnLine J. Biol. Sci. 7: 44-51.

17. Martin $R$, Soberon $N$, Vaneechoutte $M$, Florez $A B$, Vazquez $F$, Suarez JE. 2008. Characterization of indigenous vaginal lactobacilli from healthy women as probiotic candidates. Int. Microbiol. 11: $261-266$.

18. Kumar S, Stecher G, Tamura K. 2016. MEGA7: Molecular evolutionary genetics analysis version 7.0 for bigger datasets. Mol. Biol. Evol. 33: 1870-1874.

19. Jiao $Y$, Cody GD, Harding AK, Wilmes P, Schrenk M, Wheeler KE, et al. 2010. Characterization of extracellular polymeric substances from acidophilic microbial biofilms. Appl. Environ. Microbiol. 76: 2916-2922.

20. Lowry OH, Rosebrough NJ, Farr AL, Randall RJ. 1951. Protein measurement with the Folin phenol reagent. J. Biol. Chem. 193: 265-275.

21. Cataldo DA, Maroon M, Schrader LE, Youngs VL. 1975. Rapid colorimetric determination of nitrate in plant tissue by nitration of salicylic acid. Commun. Soil Sci. Plant Anal. 6: 71-80.

22. RayChaudhuri S, Thakur AR, Gantayet LM. 27. 01. 2017. Patent no. 201731003023. Bio-fertilizer production from bacterial consortium.

23. Das S, Mukherjee I, Sudarshan M, Sinha TP, Thakur AR, RayChaudhuri S. 2012. Bacterial isolates of marine coast as commercial producer of protease. OnLine J. Biol. Sci. 12: 96-107.

24. DebRoy S, Bhattacharjee A, Thakur AR, RayChaudhuri S. 2013. Draft Genome of a nitrate and phosphate accumulating Bacillus sp MCC0008. Genome A. 1: e00189-12.

25. Mishra M, Jain S, Thakur AR, RayChaudhuri S. 2014. Microbial community in packed bed bioreactor involved in nitrate remedi- 
ation from low level radioactive waste. J. Basic Microbiol. 54: 198203.

26. DebRoy S, Mukherjee P, Roy S, Thakur AR, RayChaudhuri S. 2013. Draft Genome of a phosphate accumulating Bacillus $\mathrm{sp}$ WBUNB004. Genome A. 1: e00251-12.

27. RayChaudhuri S, Sharmin J, Banerjee S, Jayakrishnan U, Saha A, Mishra $M$, et al. 2016. Novel microbial system developed from low level radioactive waste treatment plant for environmental sustenance. pp. 121-154. In Saleh HEDM, Rahman ROA (eds.), Management of Hazardous Wastes, Intech, Croatia.

28. Saha A, Bhushan S, Mukherjee P, Chanda C, Bhaumik M, Ghosh $M$, et al. 2017. Simultaneous sequestration of nitrate and phosphate from wastewater using a tailor made bacterial consortium in biofilm bioreactor. J. Chem. Technol. Biotechnol. 93: 1279-1289.

29. RayChaudhuri S, Mukherjee I, Datta D, Chanda C, Krishnan GP, Bhatt S, et al. 2016. Developing tailor-made microbial consortium for effluent remediation. pp. 17-35. In Rahman ROA, SalehHEDM (eds.), Nuclear Material Performance, Intech.

30. Oh HM, Ku YH, Ahn KH, Jang KY, Kho YH, Kwon GS, et al. 1995. Biological treatment of phenolic Industrial wastewater by a mixed culture immobilized on ceramic beads. Korean J. Microbiol. Biotechnol. 23: 755-762.

31. Park AR, Koo BS, Kim JS, Kim EJ, Lee HC. 2016. Lactulose produc- tion using Immobilized cells including thermostable Cellobiose 2-epimerase. Miocrobiol. Biotechnol. Lett. 44: 504-511.

32. Goldman JC, Caron DA, Dennett MR. 1987. Regulation of gross growth efficiency and ammonium regeneration in bacteria by substrate C: N ratio. Limnol. Oceanogr. 32: 1239-1252.

33. Ghoshal T, Ghosh S, Saha A, Halder N, Thakur AR, RayChaudhuri S. 2014. Combination of conventional and in-silico approach for identifying an industrially important isolate of Aeromonas. Online J. Biol. Sci. 14: 70-83.

34. Mroczkowski W, Stuczynski T. 2006. Toxic effects of ammonia volatilizing from sandy soil fertilized with ammonium salts and urea on barley crop decreases. Polish J. Environ. Stud. 15: 827-832.

35. Buresh RJ, Patrick WH.1978. Nitrate reduction to ammonium in anaerobic soil. Soil Sci. Soc. Am. J. 42: 913-918.

36. Burgin AJ, Hamilton SK. 2007. Have we overemphasized the role of denitrification in aquatic ecosystems? A review of nitrate removal pathways. Front. Ecol. Environ. 5: 89-96.

37. Chatterjee D, Thakur AR, Raychaudhuri S. 2013. Draft genome sequence of ammonia-Producing Acinetobacter sp. Strain MCC2139 from Dairy Effluent. Genome Annouc. 1: 410-413.

38. Sharma NK, Goswami B, Gajjar B, Jain C, Soni D, Patel K. 2011. Utilization of Amul Dairy effluent for agriculture practices. Int. J. Environ. Sci. 2: 22-32. 